\title{
Snakes on a plan
}

\author{
John Bozinovski, MD, MSc
}

\footnotetext{
From the Division of Cardiac Surgery, University of British Columbia and the Royal Jubilee Hospital, Victoria, British Columbia, Canada.

Disclosures: Author has nothing to disclose with regard to commercial support.

Received for publication Nov 24, 2017; accepted for publication Dec 4, 2017; available ahead of print Jan 23, 2018.

Address for reprints: John Bozinovski, MD, MSc, 106-2020 Richmond Rd, Victoria, British Columbia, V8R-6R5,

Canada (E-mail: john.bozinovski@ubc.ca).

J Thorac Cardiovasc Surg 2018;155:1401-2

$0022-5223 / \$ 36.00$

Copyright (c) 2017 by The American Association for Thoracic Surgery

https://doi.org/10.1016/j.jtcvs.2017.12.034
}

Our colleagues in Valencia provide a case report and video showing their technique for the reattachment of intercostal arteries (ICAs) during repair of a thoracoabdominal aortic aneurysm (TAAA), in this case an extent I TAAA. ${ }^{2}$ They describe their rationale for use of the "snake technique" in mitigating spinal cord injury (SCI). Despite the advancement of adjunctive measures, SCI occurs in a significant proportion of patients undergoing TAAA repair. ${ }^{3}$ Their accompanying video well complements the article.

The importance of ICA reattachment has been debated, with some suggesting reestablishment of ICA perfusion is less important than preemptive occlusion of ICAs. ${ }^{4}$ However, the more pervasive opinion is that ICA reperfusion significantly affects SCI outcome, especially in more extensive TAAA pathology. ${ }^{5,6}$ The finding that endovascular exclusion of extensive descending thoracic pathology (essentially immediate occlusion of the ICAs) still results in SCI rates of $3 \%$ to $10 \%{ }^{7}$ supports the latter assumption.

The snake technique has been adopted by several groups since being described by Woo and colleagues. ${ }^{1}$ Fletcher-Sanfeliu and colleagues ${ }^{2}$ provide some valuable suggestions to consider when performing the snake technique. They also call attention to some advantages and disadvantages that the snake technique has over other techniques, such as the ICA island patch and the endto-end interposition graft. Concerns that the ICA island patch leaves behind a portion of diseased aorta that could become aneurysmal led to an end-to-end anastomosed interposition graft technique. However, the small caliber of the ICAs produces high resistance to flow with potential thrombosis of the graft or ICAs. The snake technique addresses this latter concern because high outflow through the distal reattachment back onto the main graft limits the risk of graft thrombosis. In addition, the snake technique more readily facilitates reattachment of multiple ICAs, thereby reducing resistance to outflow, increasing distal runoff, and providing a broader spinal cord territory of reperfusion.

However, we then return to the original problem of leaving behind a larger patch of aorta that could become well.

\section{References} 2007;46:421-6. 1670-7.

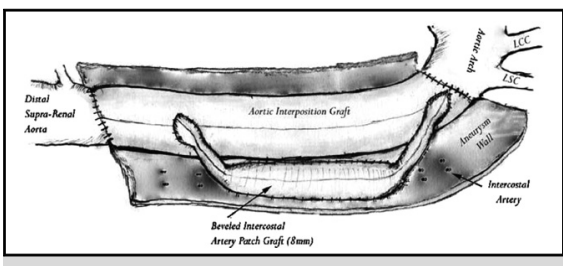

Snake technique. Reproduced with permission from Woo and colleagues. ${ }^{1}$

\section{Central Message}

The snake technique to facilitate spinal cord reperfusion should be on the aortic surgeon's plan as a potential need when performing TAAA replacement surgery.

See Article page 1399.

aneurysmal with time. Experience may show us that this is easily addressed by endovascular exclusion of the proximal entry and distal exit of the snake graft, or perhaps by the sequential exclusion of the proximal connection temporally followed by distal connection exclusion, all under evoked potential monitoring to assess for, and further attenuate, the risk of SCI. Staging repairs has been shown to lower the risk of SCI in open ${ }^{8}$ and endovascular repair, ${ }^{9,10}$ so this benefit might extend to addressing snake graft patch aneurysm by staged endovascular treatment as

Superimposed on all of this is that although it seems reasonable that a snake technique better protects against SCI than other methods, evidence for this is absent. Among the many tools available to perform TAAA repair successfully, the snake technique is one of the more novel ones. Its potential use during TAAA repair should be part of any aortic surgeon's plan.

1. Woo EY, Mcgarvey M, Jackson BM, Bavaria JE, Fairman RM, Pochettino A. Spinal cord ischemia may be reduced via a novel technique of intercostal artery revascularization during open thoracoabdominal aneurysm repair. $J$ Vasc Surg.

2. Fletcher-Sanfeliu D, Garcia-Granero A, Rueda Munoz C, Martin-Gonzalez I. Type I thoracoabdominal aortic aneurysm: Intercostal reimplantation by the "snake" technique. J Thorac Cardiovasc Surg. 2018;155:1399-400.

3. Coselli JS, Bozinovski J, LeMaire SA. Open surgical repair of 2286 thoracoabdominal aortic aneurysms. Ann Thorac Surg. 2007;83:S862-4.

4. Etz CD, Halstead JC, Spielvogel D, Shahani R, Lazala R, Homann TM, et al. Thoracic and thoracoabdominal aneurysm repair: is reimplantation of spinal cord arteries a waste of time? Ann Thorac Surg. 2006;82:

5. Shiya N, Yasuda K, Matsui Y, Sakuma M, Sasaki S. Spinal cord protection during thoracoabdominal aortic aneurysm repair: results of selective reconstruction of 
the critical segmental arteries guided by evoke spinal cord potential monitoring. J Vasc Surg. 1995;21:970-5.

6. Safi HJ, Miller CC, Carr C, Iliopoulos DC, Dorsay DA, Baldwin JC. Importance of intercostal artery reattachment during thoracoabdominal aortic aneurysm repair. J Vasc Surg. 1998;27:58-68.

7. Etz CD, Weigang E, Hartert M, Lonn L, Mestres CA, Di Bartolomeo R, et al. Contemporary spinal cord protection during thoracic and thoracoabdominal aortic surgery and endovascular aortic repair: a position paper of the vascular domain of the European Association for Cardio-Thoracic Surgery. Eur J Cardiothorac Surg. 2015;47:943-57.
8. Etz CD, Zoli S, Mueller CS, Bodian CA, Di Luozzo G, Lazala R, et al. Staged repair significantly reduces paraplegia rate after extensive thoracoabdominal aortic aneurysm repair. J Thorac Cardiovasc Surg. 2010;139:1464-72.

9. Lioupis C, Corriveau MM, MacKenzie KS, Obrand DI, Steinmetz OK, Ivancev K, et al. Paraplegia prevention branches: a new adjunct for preventing or treating spinal cord injury after endovascular repair of thoracoabdominal aneurysms. J Vasc Surg. 2011;54:252-7.

10. O'Callaghan A, Mastracci TM, Eagleton MJ. Staged endovascular repair of thoracoabdominal aortic aneurysms limits incidence and severity of spinal cord ischemia. J Vasc Surg. 2015;61:247-54. 